УДК 33

$10.17213 / 2075-2067-2021-3-126-134$

\title{
РАЗВИТИЕ ИНФОРМАЦИОННО-КОММУНИКАЦИОННОЙ СРЕДЫ В НАЛОГОВОМ АДМИНИСТРИРОВАНИИ
}

\author{
() 2021 г. И. В. Гашенко, Ю. С. Зима \\ Ростовский государственный экономический университет (РИНХ), \\ 2. Ростов-на-Дону, Россия
}

Цель исследования. B статье оценивается влияние информаџионных технологий на эффективность налогового администрирования и развитие сервис-ориентированного подхода в деятельности налоговых органов с налогоплательщиками. В настоящее время ФНС России ориентирована на создание новой модели циифровой налоговой системь для внедрения бесконтактного взаимодействия участников налоговых отношений и превращения налоговой службы из фискального органа в сервисную компанию для удовлетворения интересов налогоплательщиков, активизации их деятельности и добровольного исполнения налоговых обязательств в рамках создания естественной доверительной средьл.

В перспективе инновачионные налоговые сервисы должны быть полностью интегрированы в бизнес-среду для гарантированных стабильных государственных доходов и корректности уплаты налоговых платежей, поэтому избранная тема исследования является актуальной.

Ключевые слова: налоговое администрирование; информационно-коммуникационная среда; информационные технологии; модель цифрровой экономики; участники налоговых отношений; налоговые органы; налогоплательщики; автоматизированные комплексы; сервисные услуги.

\section{DEVELOPMENT OF INFORMATION AND COMMUNICATION ENVIRONMENT IN TAX ADMINISTRATION}

\author{
(C) 2021 I. V. Gashenko, Yu. S. Zima
}

\section{Rostov State University of Economics (RSUE), Rostov-on-Don, Russia}

The purpose of the study. The article assesses the impact of information technology on the efficiency of tax administration and the development of a service-oriented approach in the activities of tax authorities with taxpayers. As part of the creation of tax liabilities as part of the creation of a trust environment.

Research prospects. In the future, innovative tax services should be fully integrated into the business environment for quaranteed stable government revenues and correct payment of tax payments. Therefore, the selected research topic is relevant.

Key words: tax administration; information and communication environment; information technology; digital economy model; participants in tax relations; tax authorities; taxpayers; automated complexes; services. 
В условиях кризисов хозяйственных систем налогообложение является одним из наиболее действенных и наиболее популярных рычагов государственного воздействия на экономическую ситуацию. Естественно, что перечень доступных налоговых инструментов достаточно широк и сейчас гибко применяется в зависимости от фазы экономического цикла. С 2015 г. в России активно внедряются информационные технологии в налоговой сфере для повышения качества и эффективности государственного управления в области налогообложения для стабильного поступления налогов и повышения качества предоставления услуг налогоплательщикам. И, конечно же, информационные технологии позволяют создать основу для проведения аналитической работы и обеспечения информационно-технологической поддержки в выполнении задач налогового администрирования. А эффективность налогового администрирования во многом зависит от развития информационно-коммуникационной среды взаимодействия участников налоговых отношений, которая повышает прозрачность, простоту документооборота и уплаты налоговых обязательств.

За последние десять лет цифровые преобразования стали основным движущим фактором эволюционного изменения всего окружающего мира. Сегодня цифровая трансформация имеет широкое применение в глобальной экономике: возникают новые рынки, новые производства, новые программные продукты, формы денег, способы организации бизнеса. Все эти изменения связаны не только с появлением интернета и развитием IT-сферы, но и с изменением парадигмы мышления населения планеты, конечно же, это касается в том числе и участников налоговых отношений.

Лидирующие позиции по уровню развития информационно-коммуникационных технологий (ИКТ) принадлежат развитым государствам - Исландии, Южной Корее и Дании. РФ занимает 45-ю позицию среди 176 стран в мире и показывает ежегодное улучшение показателя развития информационно-коммуникационных технологий. Высокие показатели развития ИКТ стали возможными благодаря распространению сети Интернет. В таблице 1 представлен показатель индекса развития информационно-коммуникационных технологий (ИКТ) по странам мира по состоянию на 01.01.2018 г. ${ }^{1}$

Целевой интернет-аудиторией в Исландии и Норвегии являются 98 \% граждан в возрасте от 15 до 74 лет, в Италии и Греции $71 \%$ и $70 \%$ соответственно, наименьший показатель охвата населения интернет-технологиями имеет Бразилия - всего $61 \%$.

Россия занимает одно из ведущих мест среди стран мира по внедрению информационных технологий в деятельности налоговых органов. Официальный сайт ФНС РФ занимает стабильно первое место по посещаемости среди сайтов всех государственных органов и организаций, что свидетельствует о том, что представленная на этом сайте информация и возможности ее применения востребованы всеми участниками налоговых правоотношений. По данным ФНС РФ, в информационной среде ФНС России хранятся и используются сведения более чем на 4,5 млн. организаций, около 4 млн. ИП, более 150 млн. физических лиц. Ежегодно налогоплательщики направляют более 50 млн. налоговых деклараций, обрабатывается более 62 млн. справок формы 2-НДФЛ. Всего объем обрабатываемых данных в информационной системе ФНС России составляет 4 петабайта данных.

На сегодня из действующих цифровых технологий на официальном сайте ФНС РФ используются более 50 электронных сервисов и размещено 40 видеороликов, которые доступно рассказывают, как пользоваться сервисами. Безусловно, ключевыми сервисами являются личные кабинеты для всех категорий налогоплательщиков, уже используемые в практике налоговых органов.

Важное звено в работе налоговых органов - налоговое администрирование, поэтому в налоговом администрировании активно применяются следующие информационные технологии, такие как:

- централизованная база данных, основанная на системе федеральной обработки данных (ЦОД);

1 Рейтинг стран мира по уровню развития информационно-коммуникационных технологий / Гуманитарный портал. URL: https://gtmarket.ru/ratings/ict-development-index (дата обращения: 06.05.2021г.). 


\section{Индекс развития информационно-коммуникационных технологий (ИКТ) по странам мира за 2010-2017 гг.}

\begin{tabular}{|l|c|c|c|c|c|c|c|}
\hline \multicolumn{1}{|c|}{ Страны } & 2010 & 2011 & 2012 & 2013 & 2015 & 2016 & 2017 \\
\hline Южная Корея & 8,64 & 8,56 & 8,81 & 8,85 & 8,93 & 8,8 & 8,85 \\
\hline Исландия & 8,19 & 8,17 & 8,64 & 8,58 & 8,86 & 8,78 & 8,98 \\
\hline Дания & 8,18 & 8,29 & 8,78 & 8,86 & 8,88 & 8,68 & 8,71 \\
\hline Норвегия & 8,16 & 7,52 & 8,35 & 8,39 & 8,49 & 8,45 & 8,47 \\
\hline Нидерланды & 7,82 & 7,82 & 8,36 & 8,38 & 8,53 & 8,4 & 8,49 \\
\hline Люксембург & 7,82 & 7,76 & 8,19 & 8,26 & 8,59 & 8,4 & 8,47 \\
\hline Япония & 7,73 & 7,76 & 8,15 & 8,22 & 8,47 & 8,32 & 8,43 \\
\hline Великобритания & 7,62 & 7,75 & 8,28 & 8,5 & 8,75 & 8,53 & 8,65 \\
\hline Швейцария & 7,6 & 7,68 & 7,94 & 8,11 & 8,56 & 8,66 & 8,74 \\
\hline Гонконг (Китай) & 7,41 & 7,68 & 8,08 & 8,28 & 8,52 & 8,47 & 8,61 \\
\hline Чехия & 6,3 & 6,17 & 6,57 & 6,72 & 7,21 & 7,06 & 7,16 \\
\hline Португалия & 6,15 & 6,05 & 6,57 & 6,67 & 6,93 & 6,88 & 7,13 \\
\hline Словакия & 5,96 & 5,86 & 6,3 & 6,58 & 6,82 & 6,91 & 7,06 \\
\hline Россия & $\mathbf{5 , 5 7}$ & $\mathbf{6}$ & $\mathbf{6 , 4 8}$ & $\mathbf{6 , 7}$ & $\mathbf{6 , 9 1}$ & $\mathbf{6 , 9 1}$ & $\mathbf{7 , 0 7}$ \\
\hline
\end{tabular}

- автоматизированные комплексы контроля (АИС «Налог-3», АСК НДС-3 - автоматизированные системы контроля налоговых деклараций по НДС за правомерностью возмещения налога, СУР АСК НДС - система управления рисками для сопоставления сведений об операциях контрагентов);

- единая государственная автоматизированная информационная система учета объема производства и оборота этилового спирта, алкогольной и спиртосодержащей продукции (ЕГАИС);

- онлайн-кассы (онлайн-обмен данными между торговыми точками и налоговой службой при помощи контрольно-кассовой техники);

- идентификация товаров и услуг в контексте налогообложения (маркировка товаров - RFID метки и мониторинг их оборота);

- развитие IT-инфраструктуры Единого реестра ЗАГС;

— технологии blok-chain в цифровой экономике;

- развитие интернета вещей.

Большое значение имеет внедрение и активное использование официальных приложений и сервисов ФНС России для налогоп- лательщиков (личный кабинет юридических, ИП и физических лиц, «НДС-офис интернеткомпании», Единый реестр субъектов малого и среднего предпринимательства, Государственная регистрация юридических лиц и ИП, «Риски бизнеса: проверь себя и контрагента», «Прозрачный бизнес», Оплата налогов и пошлин, Налоговые калькуляторы, «Мой налог», «Налоги ФЛ», справочная информация и др.).

Сегодня формирование модели сервисориентированного налогового администрирования полностью предполагает развитие электронного взаимодействия налоговых органов с налогоплательщиками. Активное внедрение информационных технологий поможет создать систему добровольного соблюдения налогового законодательства, т.е. повысит уровень взаимного доверия между государством и налогоплательщиками. Таким образом, новые инновационные методы налогового администрирования, основанные на современных информационных технологиях, позволят практически полное исключить очное взаимодействие налогового органа и налогоплательщика и перейти на бесконтактное общение. Как пример: внедренный 
в практику налоговый мониторинг крупнейших налогоплательщиков, предполагающий полную интеграцию налоговых сервисов в бизнес-среду, автоматическое исполнение ими налоговых обязательств. Так, за последние пять лет проведения налогового мониторинга в РФ количество его участников увеличилось в 30 раз (в 2021 г. - 209 участников из 15 отраслей). В 2020 г. ОЭСР признала налоговый мониторинг ФНС России одной из лучших международных практик по выстраиванию цифрового взаимодействия между государством и бизнесом. Помимо него, в этот список вошел опыт Сингапура, Норвегии, Австралии, Испании, Финляндии и Кении.

В соответствии с Концепцией развития налогового мониторинга ФНС РФ будет достигнуто поэтапное снижение порога для добровольного присоединения компаний к системе - в три раза по каждому из обязательных критериев. Так, с 2022 года в налоговый мониторинг смогут войти организации, объем годовых доходов которых составляет 1 млрд. рублей, активы - 1 млрд. рублей, совокупная сумма исчисленных за год налогов - 100 млн. рублей. При этом будут учитываться не только исчисленные компанией налоги, но и суммы НДФЛ и страховых взносов. Таким образом, число потенциальных участников налогового мониторинга может возрасти до 3,9 тыс. Напомним, что сейчас к системе налогового мониторинга могут подключаться организации, годовой доход которых составляет 3 млрд. рублей, активы - 3 млрд. рублей, сумма исчисленных за год налогов - 300 млн. рублей.

С 2021 года к налоговому мониторингу присоединились 10 компаний группы «Роснефть», включая ПАО «НК «Роснефть», 17 дочерних компаний группы «Газпром», пять дочерних обществ группы «Новатэк», четыре «дочки» группы «Лукойл», «Норильский никель» и Московская биржа.

Среди новых участников есть и иностранные компании: Procter\&Gamble с двумя «дочками», «Леруа Мерлен», Metro Cash\&Carry, «Нестле», «Ферреро», «Тиккурила».

Также заявления на налоговый мониторинг представили семь компаний, администрируемых в территориальных налоговых органах, в том числе «Роснано».
В рамках построения цифровой модели налоговой системы для того, чтобы добиться добровольного соблюдения налогового законодательства, ФНС России ставит для себя следующие задачи:

- налоговое администрирование на основе больших данных (Big Data) и онлайнсервисов;

- полная интеграция налоговых сервисов в естественную среду;

- отказ от необходимости взаимодействовать с инспекциями в режиме «офлайн»бесконтактное взаимодействие между участниками налоговых отношений;

- автоматическое выполнение налоговых обязательств на основе цифровизации налоговых процессов;

- переход от пресечения к предупреждению налоговых нарушений; бизнеса;

- практически полная прозрачность

- новый уровень доверия между государством и обществом.

Однако существуют барьеры, которые нужно преодолевать, чтобы создать современную цифровую администрацию. На пути цифровизации налоговых систем встают следующие проблемы.

1. Цифровое исключение отдельной части налогоплательщиков, которые не имеют возможности или не хотят использовать цифровые методы для взаимодействия с государственными налоговыми органами ввиду отсутствия у пользователей необходимых для этого знаний и навыков, личные убеждения граждан, инвалидность, удаленное местоположение, отсутствие технических возможностей и других факторов.

2. Проблема кибербезопасности и сохранения конфиденциальных данных, агрегированных в информационно-аналитических системах налоговых органов. Хакерские атаки, получение доступа к конфиденциальной информации являются серьезными угрозами в любой сфере. Мы не должны забывать, что в информационно-аналитических системах налоговых органов эти угрозы особенно высоки из-за ценности и полноты содержащихся в них сведений. Со стороны налоговых органов должна быть надлежащая осмотрительность и согласованность с налогоплательщиками о ключевых рисках и мерах предосторожности. 
3. Переход к цифровой модели налоговой системы сопровождается дорогостоящим оборудованием и сложностями процесса перехода. Несмотря на очевидные преимущества оцифровки налоговых процессов, сам процесс цифровизации является длительным и может занять несколько лет, и только по истечению определенного времени проявится кумулятивный эффект применения IT-технологий в налогообложении в виде расширения спектра налоговых услуг и упрощения процедуры уплаты, сокращения схем уклонений уплаты налогов, коррупционной составляющей.

4. Нужно признать, что цифровизация налоговой системы - это не первое внедрение компьютерных технологий, а их обновление и расширение, поэтому возникла проблема переноса полных данных из имеющихся старых информационных систем в новые, который сопровождается потерей данных или их искажением. В перспективе потребуется объединение данных из различных существующих информационных систем: налоговых органов, таможенных органов и внебюджетных фондов.

Решение этих основных проблем в использовании IT-технологий в налоговой сфере позволит оказать влияние на эффективность цифровизации и будет способствовать дальнейшему развитию цифровой трансформации налоговой системы. Как следствие, элементами цифровой модели налоговой системы могут стать:

- наличие универсальных форм налоговых декларации;

- простота и лаконичность налоговой системы (оцифровка сопровождается большими возможностями автоматизации процесса налоговой проверки и исполнения налоговых обязательств в режиме реального времени, что приведет к упрощению налогового законодательства);

— высокий уровень налоговой культуры и грамотности;

- значительно сократятся масштабы теневой экономики.
В рамках развития программы частно-государственного партнерства за 2017-2019 гг. ключевыми IT-поставщиками ФНС России была оказана мощная технологическая поддержка в виде разработки электронных сервисов для активного и продуктивного взаимодействия налоговых органов и налогоплательщиков. На основании данных официального портала госзакупок и базы данных «Контур.Фокус», совокупный объем заключенных ФНС РФ с ведущими топ-5 ІТ-подрядчиками за 2017-2019 гг. составили:

— IBS - 5067358114 руб. (обслуживание оборудования и ПО АИС, других систем, развитие ЕГР ЗАГС и ЕГР населения России);

— «Форс» - 5000435940 руб. (создание и модернизация систем АИС Налог-3);

— «Компьюлинк» - 2234092755 руб.;

— «Системный софт»-1911883469руб.;

- «Инлайн Технолоджис»

1804509412 руб. ${ }^{2}$.

Таким образом, приведенные данные свидетельствуют о больших объемах государственных средств, выделяемых на развитие и внедрение IT-технологий с целью повышения эффективности методов налогового администрирования. Российские IT-компании с 2021 г. получили налоговые льготы по налогу на прибыль организаций и страховым взносам. Так, ставка по налогу на прибыль снижена до $3 \%$ в части, отчисляемой в федеральный бюджет, и $0 \%$ - для региональной части налога. Также бессрочно установлены пониженные тарифы страховых взносов в совокупном размере 7,6\%. При этом уведомлять о праве пользования льготой не требуется, она предоставляется автоматически ${ }^{3}$.

Ввиду очевидной значимости цифровых технологий, которые внедряются во все сферы жизнедеятельности, дискуссируется вопрос о внедрении новых налогов на цифровую прибыль, необходимо ввести единый подход к реформированию основ международной системы налогообложения транснациональных цифровых компаний. В частности, возникают идеи о введении таких новых налогов, как налог на некоторые виды циф-

2 Информационные технологии в Федеральной налоговой службе РФ (26.02.2021). URL: https://www. tadviser.ru/index.php/ (дата обращения: 06.05.2021 г.).

3 Налоговые льготы для IT-компаний: как применять с 2021 года? / Информационно-правовой портал ГАPAHT.PY. URL: www.garant.ru / (дата обращения: 06.05.2021 г.). 
ровых операций, удерживаемый с источника, акциз на электронные услуги и в качестве временной меры - налог на выручку цифрового предприятия (Еврокомиссия предложила ставку 3\%). Идея налога на выручку нашла отражение в односторонних действиях в Греции, Индии, Италии и Великобритании. Оборотные налоги были введены для целевых секторов, таких как налог Венгрии на цифровую рекламу и сбор Италии с цифровых транзакций. Данное предложение Европейского союза касается только компаний с глобальной выручкой более 750 млн. евро и налогооблагаемой выручкой в странах членах ЕС более 50 млн. евро в год, которые продают онлайновую рекламу или являются онлайновыми торговыми площадками (Google, Facebook, Uber и др.).

В целях развития информационно-коммуникационной среды в налоговом администрировании с применением цифровых технологий ставится стратегическая задача превращения налоговой службы из фискального органа в сервисную компанию, ориентированную на удовлетворение интересов налогоплательщиков, активизацию их деятельности по выполнению своих налоговых обязательств на добровольной основе в рамках создания условий естественной доверительной среды. В перспективе налоговые сервисы должны быть полностью интегрированы в бизнес-среду.

ФНС РФ постоянно модернизирует существующие онлайн-сервисы, а также разрабатывает и внедряет новые информационные продукты. В 2021 году разработан обширный список мероприятий, связанных с цифровыми технологиями ${ }^{4}$ :

1) одним из наиболее глобальных можно назвать разработку концепции автоматизированной информационной системы ФНС четвертого поколения (АИС «Налог-4») с учетом динамического внешнего окружения и импортозамещения;

2) до конца 2021 г. создать Единый федеральный информационный регистр, содержащий сведения о населении РФ (ФГИС ЕРН) на базе ЕГР «ЗАГС», в которой будет находиться более 30 видов сведений о граж- данах, но информация о доходах и налоговых поступлениях в нем учитываться не будет, что позволит своевременно оказывать адресную социальную помощь без истребования информации от других органов и регионов, сократить количество мошеннических действий при получении мер социальной поддержки, коррупцию;

3) создать ФНС России совместно с банками цифровую сервисную платформу для обмена сведений о налогоплательщике при оказании финансовых и иных услуг. В связи с введением с 01.01.2021 г. НДФЛ по банковским вкладам свыше 1 млн. руб. налоговые органы на основании полученных данных будут сами направлять уведомления физическим лицам по налоговым обязательствам по НДФЛ, которые должны быть исполнены не позднее 1 декабря года, следующего за налоговым периодом.

4) внедрить электронную систему «УСН-онлайн» для автоматического учета доходов в оперативном режиме с целью исключения обязанности предоставления налоговой декларации для субъектов малого и среднего предпринимательства. Таковых в ФНС насчитывают 1,2 млн. в России. Налоговый орган будет исчислять налог самостоятельно на основе данных, полученных от онлайн-касс;

5) создать новый единый сводный реестр задолженности по платежам в бюджет для взаимодействия ФНС РФ с ФССП для повышения эффективности взыскания задолженности по обязательным платежам;

6) для разрешения досудебных налоговых споров ввести в эксплуатацию в июне 2021 г. ПО «Налоговые споры» как подсистему в АИС «Налог-3», что позволит получать, обрабатывать, вести учет, анализировать и передавать данные о возникновении споров. Также будет разработан порядок рассмотрения жалоб посредством видеоконференцсвязи;

7) ФНС РФ будет бесплатно выдавать юридическим лицам и индивидуальным предпринимателям электронные цифровые подписи (ЭЦП), используемые для формирования налогового документооборота;

4 Информационные технологии в Федеральной налоговой службе РФ (26.02.2021). URL: https://www. tadviser.ru/index.php/ (дата обращения: 06.05.2021 г.). 
8) с мая 2020 г. активно внедряется новый цифровой сервис ФНС РФ - Удостоверяющий центр (УЦ), на основе которого юридические лица, индивидуальные предприниматели и нотариусы будут обеспечены сертификатами квалифицированной электронной подписи;

9) ФНС получит онлайн-доступ к бухгалтерской и налоговой отчетности компаний, представляющих средний бизнес. Соответствующие поправки в Налоговый кодекс вносит Минфин РФ.

Таким образом, сформирован новый концептуальный подход налогового администрирования - «цифровая модель налоговой системы». Активное внедрение инновационных методов налогового администрирования путем использования массива автоматизированных информационных систем контроля и онлайн-сервисов создают комфортную информационно-коммуникационную среду для участников налоговых отношений и улучшения качества бюджетного планирования, гарантированных стабильных государственных доходов и корректности уплаты налогов.

\section{Литература}

1. Башкирова Н.Н. Анализ социальноэкономических последствий реформирования НДС / Н.Н. Башкирова, С. Р. Эштиева// Проблемы анализа риска. — 2017. — Т. 14. №4. - C. 14-23.

2. Динамика абсолютных значений и темпа роста ВВП России в постоянных ценах в 2000-2022 гг. [Электронный реcypc] / International Monetary Fund. - Peжим доступа: https://www.imf.org/external/ pubs/ft/weo/2017/01/weodata/weorept.aspx $? \mathrm{sy}=2000 \&$ ey $=2022 \& \mathrm{scsm}=1 \& \mathrm{ssd}=1 \&$ sor $\mathrm{t}=$ subject\&ds $=\% 2 \mathrm{C} \& \mathrm{br}=0 \& \mathrm{pr} 1 . \mathrm{x}=67 \& \mathrm{pr} 1$. $\mathrm{y}=8 \& \mathrm{c}=922 \& \mathrm{~s}=\mathrm{NGDP}_{-} \mathrm{R} \% 2 \mathrm{CNGDP}$ RPCH\&grp=0\&a= (Дата обращения: 06.05.2021 г.).

3. Информационные технологии в Федеральной налоговой службе РФ (26.02.2021) [Электронный ресурс]. - Режим доступа: https://www.tadviser.ru/index.php/ (Дата обращения: 06.05.2021 г.).

4. Михайловская Е., Ропотагеvа Ји. Налоговые меры по обеспечению устойчивого раз- вития российской экономики в период пандемии коронавируса. 2020. [Электронный ресурс]. - Режим доступа: https://www.dlapiper. com/ru/russia/insights/publications/2020/04/ tax-measures-in-russia/ (Дата обращения: 05.05.2021).

5. Налоговые льготы для IT-компаний: как применять с 2021 года? [Электронный ресурс] / Информационно-правовой портал ГАРАНТ.РУ. - Режим доступа: www.garant. ru / (Дата обращения: 06.05.2021 г.).

6. Налоговая безопасность: монография для магистров вузов, обучающихся по направлениям подготовки «Экономика», «Юриспруденция» / Под ред. О.А. Мироновой. Серия «Magister». - М.: ЮНИТИ-ДАНА: Закон и право, 2019. - 463 с.

7. Программа «Цифровая экономика Российской Федерации», утвержденная распоряжением Правительства Российской Федерации от 28 июля 2017 г. №1632-р [Электронный ресурс]. - Режим доступа: http://static. government.ru/media/files/9gFM4FHj4PsB79I 5v7yLVuPgu4bvR7M0.pdf (Дата обращения: 06.05.2021 г.).

8. Разуваева Е.Б., Якупова Л. Уклонение от уплаты налогов: способы уклонения и методы решения / Е.Б. Разуваева, Л.Р. Якупова// Вестник современных исследований. 2018. - №6.2 (21). — С. 265-267.

9. Рейтинг стран мира по уровню развития информационно-коммуникационных технологий [Электронный ресурс] / Гуманитарный портал. - Режим доступа: https:// gtmarket.ru/ratings/ict-development-index (Дата обращения: 06.05.2021 г.).

10. Henry E. Corporate tax avoidance: data truncation and loss firms / E. Henry, R. Sansing // Review of Accounting Studies. - 2018. №23 (3). - P. 1042-1070.

11. Malik $S$. An experimental analysis of tax avoidance policies / S. Malik, B. Mihm, F. Timme // International Tax and Public Finance. - 2018. — №25 (1). — P. 200-239.

\section{References}

1. Bashkirova N.N. Analiz social'nojekonomicheskih posledstvij reformirovanija NDS [Analysis of the socio-economic consequences of VAT reform] / N. N. Bashkirova, S.R. Jeshtieva // Problemy analiza riska 
[Problems of risk analysis]. — 2017. Vol. 14. - №4. - Pp. 14-23.

2. Dinamika absoljutnyh znachenij i tempa rosta VVP Rossii v postojannyh cenah v 20002022 gg. [Dynamics of absolute values and the growth rate of Russia's GDP in constant prices in 2000-2022] [Jelektronnyj resurs] / International Monetary Fund. - URL: https://www.imf.org/ external/pubs/ft/weo/2017/01/weodata/weorept. aspx $?$ sy $=2000 \&$ ey $=2022 \& \operatorname{scsm}=1 \&$ ssd $=1 \&$ s ort $=$ subject\&ds $=\% 2 \mathrm{C} \& b r=0 \& p r 1 . x=67 \& \mathrm{pr} 1$. $\mathrm{y}=8 \& \mathrm{c}=922 \& \mathrm{~s}=\mathrm{NGDP}$ R\% 2CNGDP RPCH\&grp $=0 \& \mathrm{a}=$ (Date accessed: 06.05.2021 g.).

3. Informacionnye tehnologii v Federal'noj nalogovoj sluzhbe RF [Information technologies in the Federal Tax Service of the Russian Federation] (26.02.2021) [Jelektronnyj resurs]. — URL: https://www.tadviser.ru/index. php/ (Date accessed: 06.05.2021 g.).

4. Mihajlovskaja E., Ponomareva Ju. Nalogovye mery po obespecheniju ustojchivogo razvitija rossijskoj jekonomiki $\mathrm{V}$ period pandemii koronavirusa [Tax measures to ensure the sustainable development of the Russian economy during the coronavirus pandemic].2020. [Jelektronnyj resurs]. — URL: https:// www.dlapiper.com/ru/russia/insights/ publications/2020/04/tax-measures-in-russia/ (Date accessed: 05.05.2021).

5. Nalogovye l'goty dlja IT-kompanij: kak primenjat' s 2021 goda? [Tax benefits for IT companies: how to apply them from 2021?] [Jelektronnyj resurs] / Informacionno-pravovoj portal GARANT.RU. — URL: www.garant.ru / (Date accessed: 06.05.2021 g.).

6. Nalogovaja bezopasnost': monografija dlja magistrov vuzov, obuchajushhihsja po napravlenijam podgotovki «Jekonomika», «Jurisprudencija» [Tax security: a monograph for masters of higher education institutions studying in the areas of training «Economics», «Jurisprudence»] / In O.A. Mironova (eds.). Serija «Magister». - Moscow: JuNITI-DANA: Zakon i pravo, 2019. - $463 \mathrm{p}$.

7. Programma «Cifrovaja jekonomika Rossijskoj Federacii», utverzhdennaja rasporjazheniem Pravitel'stva Rossijskoj Federacii ot 28 ijulja 2017 g. №1632-r [The program «Digital Economy of the Russian Federation», approved by the order of the Government of the Russian Federation of July 28, 2017 №1632-r] [Jelektronnyj resurs]. URL: http://static.government.ru/media/files/9 gFM4FHj4PsB79I5v7yLVuPgu4bvR7M0.pdf (Date accessed: 06.05.2021 g.).

8. Razuvaeva E.B., Jakupova L. Uklonenie ot uplaty nalogov: sposoby uklonenija i metody reshenija [Tax evasion: methods of evasion and methods of solution] / E.B. Razuvaeva, L.R. Jakupova // Vestnik sovremennyh issledovanij [Bulletin of Modern Research]. 2018. — №6.2 (21). — Pp. 265-267.

9. Rejting stran mira po urovnju razvitija informacionno-kommunikacionnyh tehnologij [Rating of the countries of the world on the level of development of information and communication technologies] [Jelektronnyj resurs] / Gumanitarnyj portal [Humanitarian Portal]. — URL: https:// gtmarket.ru/ratings/ict-development-index (Date accessed: 06.05.2021 g.).

10. Henry E. Corporate tax avoidance: data truncation and loss firms / E. Henry, R. Sansing// Review of Accounting Studies. - 2018. №23 (3). - P. 1042-1070.

11. Malik $S$. An experimental analysis of tax avoidance policies / S. Malik, B. Mihm, F. Timme // International Tax and Public Finance. - 2018. - №25 (1). - P. 200-239. 


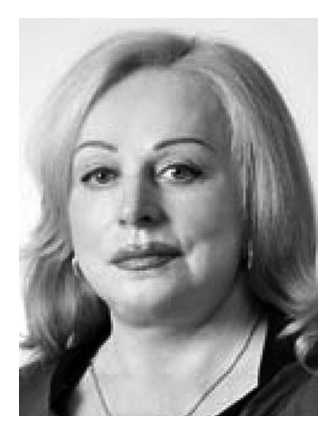

Гашенко Ирина Владиленовна - доктор экономических наук, профессор кафедры «Налоги и налогообложение» Ростовского государственного экономического университета (РИНХ). Специалист в области исследования проблемных аспектов прямого налогообложения. Советник государственной гражданской службы РФ I класса. Награждена знаком отличия «Отличник Министерства Российской Федерации по налогам и сборам». Общий стаж работы на руководящих должностях в налоговых органах составляет 25 лет, стаж преподавательской работы в университете - более 19 лет.

Gashenko Irina Vladilenovna - Doctor of Economic Sciences, Professor of the Department of Taxes and Taxation, Rostov State University of Economics (RSUE). Advisor to the State Civil Service of the Russian Federation, 1st class Awarded with the distinction «Excellent worker of the Ministry of the Russian Federation for Taxes and Duties». The total work experience in management positions in the tax authorities is 25 years, the experience of teaching at the university is over 19 years.

344002, г. Ростов-на-Дону, ул. Б. Садовая, 69

69 B. Sadovaya st., 344002, Rostov-on-Don, Russia

E-mail: gaforos@rambler.ru

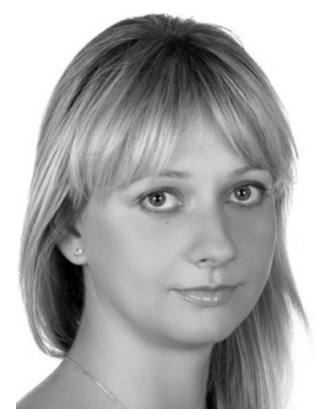

Зима Юлия Сергеевна - кандидат экономических наук, доцент кафедры «Налоги и налогообложение» Ростовского государственного экономического университета (РИНХ). Специалист в области исследования проблем и перспектив налогообложения юридических и физических лиц. Автор более 100 научных работ в российских и зарубежных изданиях, в том числе нескольких монографий. Общий преподавательский стаж - 20 лет.

Zima Yulia Sergeevna - Candidate of Economic Sciences, Associate Professor of the Department of Taxes and Taxation, Rostov State University of Economics (RSUE). Specialist in the field of researching the problems and prospects of taxation of legal entities and individuals. She is the author of over 100 scientific papers in Russian and foreign publications, including several monographs. General teaching experience for 20 years.

344002, г. Ростов-на-Дону, ул. Б. Садовая, 69

69 B. Sadovaya st., 344002, Rostov-on-Don, Russia

E-mail: zima.julia.sergeevna@gmail.com 